\title{
Effect of Mixed Foundry Sand and Rice Hull Ash on the Mechanical Properties of Concrete
}

\author{
Ali Seyedkazemi ${ }^{1}$, Meysam Mirzaeipour ${ }^{1}$, Seyed Ebrahim Vahdat ${ }^{2 *}$ \\ 1. Department of Civil Engineering, Ayatollah Amoli Branch, Islamic Azad University, Amol, Iran \\ 2. Department of Engineering, Ayatollah Amoli Branch, Islamic Azad University, Amol, Iran \\ E-mail: a.seyedkazemi@iauamol.ac.ir; e.vahdat@iauamol.ac.ir
}

Received: 15 November 2020; Accepted: 7 December 2020; Available online: 10 January 2021

\begin{abstract}
Waste foundry sand is the by-product of metal casting industry. Rice hull which is often burned after it is removed from rice is also a by-product of the agriculture industry. Disposing of these wastes leads to the environmental pollution. To optimal use of these wastes and avoid the adverse effects of dumping them, regular sand has been partially replaced with the waste foundry sand and rice hull ash pozzolan has been also used as a partial replacement for cement in making concrete. XRF, XRD and SEM experiments, compressive strength, tensile strength (Brazilian), flexural strength, modulus of elasticity and water absorption tests have been conducted. The results showed a slight decrease in compressive strength of samples in which regular sand was replaced with waste foundry sand by 15 percent; however, adding the rice hull ash to this mixture led to make a concrete comparable with control one. Also, using foundry sand in mix designs affects their physical performance. Moreover, the use of waste foundry sand in concrete is both economically and environmentally suitable.

Keywords: Recycled materials concrete; Rice hull ash; Strength properties; Waste foundry sand.
\end{abstract}

\section{Introduction}

One of the methods for achieving of sustainable products is recycling and reusing of waste materials. For this purpose, the waste material is using in making concrete and other building materials. This can even lead to improve properties, for example in concrete. Today, extensive research is being carried out on the use of recycled materials in concrete production [1].

In terms of the electrical resistivity and ultrasonic pulse velocity tests, the effect of replacing waste materials was below $14 \%$, irrespective of whether natural or recycled aggregates were used. Such promising findings pave the way for more efficient and global management with a view to steering the construction industry toward the circular economy [2].

One of these waste materials is silica sand which is being used in casting industry. Using silica sand of the casting industry instead of the bank sand or the blown sand in concrete will result in saving the natural resources and keeping them for the future production. Moreover, since the process of cement manufacturing causes serious pollution, using alternative materials such as pozzolans in concrete industry is an absolute necessity. One of these pozzolans is ash from burned rice hull. This pozzolana is a by-products of the agriculture industry, so using it instead of cement can conserve the environment and also its high levels of silica can improve the strength and the durability of the concrete [3].

Kumar and Bhardwaj [4] studied the effect of replacing regular sand with foundry sand on the strength characteristics of the concrete. In this study, water-cement ratio was 0.45 and regular sand was replaced with foundry sand in percentages of $0,10,20,30,40,50,75$ and 100. Compressive, tensile and flexural strength tests results on concrete samples in the ages of 7 and 28 days indicated that increasing the foundry sand replacement up to $50 \%$ will increase the strengths. However, if the replacement proportion exceeds $50 \%$ then the compressive strength decreases and the results are not satisfactory compared to control sample.

The results of Makul's research showed that the incorporation of untreated rice husk ash (RHA) and foundry sand waste (FDW) decreases the filling, passing ability, and segregation of high-performance self-consolidating concrete (SCC) while increasing its durability [5].

Basar and Aksoy [6] studied the potential of using foundry sand in concrete. They replaced regular sand with five percentages $(0 \%, 10 \%, 20 \%, 30 \%, 40 \%)$ of waste foundry sand. The amount of cement was $350 \mathrm{~kg} / \mathrm{m} 3$ and water-cement ratio was 0.5 . Test results showed that by increasing the replacement proportions of regular sand with waste foundry sand, the strength performance and the density of concrete will reduce and the water absorption ratio of concrete mixtures will increase. 
In Singh and Siddique's study [7], concrete samples were made by replacing natural sand with waste foundry sand with five percentages $(0 \%, 5 \%, 10 \%, 15 \%$ and $20 \%)$. In preparing these samples water-cement ratio was 0.5 . The compressive and tensile strength tests have been conducted at ages 7, 28 and 91 days, and also the modulus of elasticity and ultrasonic tests have been conducted on the concrete samples at ages 28 and 90 days. The results showed that by increasing the replacement percentage of the natural sand with waste foundry sand, the strength and durability properties of concrete samples will improve compared to the control concrete.

Sohail et al. [8] studied the results of using foundry sand on compressive, tensile and flexural strengths of hardened concrete. To this end, 21 mix designs were tested. 11 mix designs which included the controlled concrete were made of regular sand and 10 mix designs were made of waste foundry sand as a partial replacement of regular sand with percentages of 10, 20, 30, 40, 50, 60, 70, 80, 90 and 100. Test results at the ages of 7, 28 and 56 days indicated that compressive strength of all mixtures except the one with $100 \%$ replacement increased compared to the control sample. Tensile strength test showed that partial replacement up to $70 \%$ cause an increase in tensile strength of the concrete containing waste foundry sand compared to the control sample. Replacements having more than $70 \%$ waste foundry sand will result in a reduction in tensile strength. In flexural strength test also, increasing the strength was up to 50\% replacement. After this replacement percentage, flexural strength will reduce compared to the control sample.

According to Salokhe and Desai's research [9], the replacement of regular sand with waste foundry sand in the percentages of 10, 20 and 30 caused 2.33, 23.37 and 24.8\% loss of compressive strength respectively.

Guney et al. [10] reported 13.8 and $24.8 \%$ reduction in the compressive strength in the replacement ratios of 5 and $15 \%$ respectively. They concluded that the ultrafine particles of bentonite clay and finer particles of foundry sand increase the specific surface area of the particles, so these finer particles absorb the free water in the concrete paste. This leads to a lack of water in the vicinity of cement and consequently affects hydration.

Prabhu et al. [11] reported that replacing regular sand with casting sand with the percentages of 10, 20, 30, 40 and 50\% caused a reduction in the tensile strength to the amounts of 5.5, 6, 9, 16.4 and 19.9\% respectively.

According to Saraswati et al. [12], using foundry sand of 20, 40 and 60\% instead of regular sand resulted in 16, 17.9 and $26.7 \%$ loss of tensile strength where water-cement ratio was $0.4 \%$. This tensile strength reduction is attributed to the ultrafine particles of Bentonite clay in the surface of foundry sand particles. These particles cover sand like a membrane and prevent proper adhesion between the cement paste and aggregates and reduce the tensile strength of concrete.

The focus of this study is to investigate the performance of the waste materials (found sand and rice hall ash) in concrete mixture. For this aim, regular sand is partially replaced with the waste foundry sand and rice hull ash pozzolana is also used as a partial replacement for cement in making concrete. In addition, the mechanical properties of the produced concrete measured and its microstructure is also investigated.

\section{Materials and mix proportions}

In this study, to ensure the accuracy of the results, all tests were conducted at the partner laboratories of the Iranian National Standards Organization.

\subsection{Materials}

\subsubsection{Cement}

In this study, Portland cement type 1 (ASTM C150 Type I) has been used in all mix designs [13]. Chemical and physical properties of this type of cement are given in Table 1.

\subsubsection{Rice hull ash}

In this study, the rice hull ash had unit weight equal to 2090 kilograms per cubic meter and its surface area was equal to 976 square meters per kilograms.

Fig. 1 shows an illustration of the rice hull ash used in this study. X-Ray Fluorescence (XRF) analysis according to ASTM E1621-13 [14] has been employed to determine chemical composition of rice hull ash and the results are presented in Table 1.

\subsubsection{Waste foundry sand}

Waste foundry sand, used in this study, has been obtained from Amol ferrous foundry located in Iran. Its color is black and has the unit weight equal to 2180 kilograms per cubic meter and its water absorption ratio is equal to $0.42 \%$. A demonstrative example of mentioned sand is shown in Fig. 2. Chemical composition of waste foundry sand is determined via XRF analysis according to ASTM E1621-13 [14]. XRF analysis results are shown in Table 1. The chemical analysis test has been conducted through X-Ray Diffraction (XRD) method based on BS EN 13925-1 [15] which its results can be seen in the Fig. 3. Quartz and $\mathrm{SiO}_{2}$ peaks can be seen in this figure. Quartz 
is composed of continuous framework of $\mathrm{SiO}_{4}$ where each oxygen atom is being shared between two tetrahedra. Thus, the general chemical formula of Quartz is $\mathrm{SiO}_{2}$. The XRD analysis results on waste foundry sand are a clear evidence of this issue.

Table 1. Chemical and physical properties of the materials

\begin{tabular}{|c|c|c|c|c|c|c|}
\hline $\begin{array}{c}\text { Chemical } \\
\text { analysis (\%) }\end{array}$ & Cement & $\begin{array}{l}\text { Rice hull } \\
\text { ash }\end{array}$ & $\begin{array}{l}\text { Foundry } \\
\text { sand }\end{array}$ & physical analyses & Cement & $\begin{array}{c}\text { ASTM C150 } \\
\text { [13] }\end{array}$ \\
\hline $\mathrm{SiO}_{2}$ & 21.3 & 85.7 & 84.8 & Specific weight $\left(\mathrm{g} / \mathrm{cm}^{3}\right)$ & 3.15 & - \\
\hline $\mathrm{Al}_{2} \mathrm{O}_{3}$ & 4.94 & 0.61 & 3.5 & Fineness ( Blaine Test, m²/kg ) & 307 & $160 \mathrm{~min}$ \\
\hline $\mathrm{Fe}_{2} \mathrm{O}_{3}$ & 4.26 & 0.42 & 1.9 & Retained on Seive \# 170 (90 $\mu \mathrm{m})$ & 5.77 & - \\
\hline $\mathrm{CaO}$ & 62.04 & 1.6 & 1.3 & Autoclave Expansion (\%) & 0.2 & 0.8 \\
\hline $\mathrm{MgO}$ & 3.08 & 0.69 & 2.1 & Water or Normal Consistency & 23 & - \\
\hline $\mathrm{SO}_{3}$ & 1.85 & 0.46 & 0.76 & Initial Setting Time (minutes) & 154 & $45 \mathrm{~min}$ \\
\hline $\mathrm{Na}_{2} \mathrm{O}$ & 0.36 & 0.04 & 2.1 & Final Setting Time (minutes) & 210 & $375 \max$ \\
\hline $\mathrm{K}_{2} \mathrm{O}$ & 0.69 & 2.0 & 0.67 & Compressive Strength (MPa) & & \\
\hline CaO.f & 0.83 & - & - & 3 days & 20.6 & $12 \mathrm{~min}$ \\
\hline $\mathrm{P}_{2} \mathrm{O}_{5}$ & - & 0.43 & - & 7 days & 34.2 & $19 \mathrm{~min}$ \\
\hline $\mathrm{MnO}$ & - & 0.16 & - & 28 days & 52.9 & $28 \mathrm{~min}$ \\
\hline $\mathrm{SrO}$ & - & - & - & & & \\
\hline LOI & 1.28 & 7.92 & 2.88 & & & \\
\hline
\end{tabular}

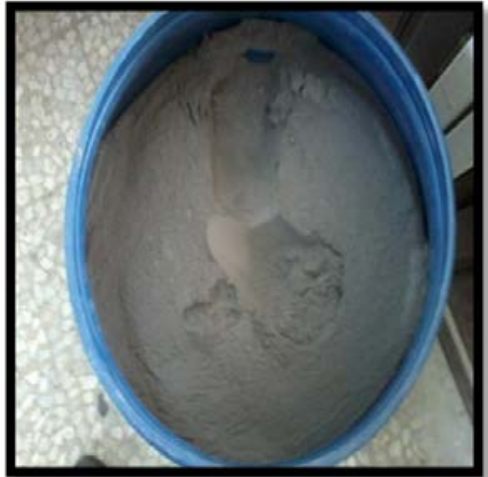

Figure 1. The image of rice hull ash

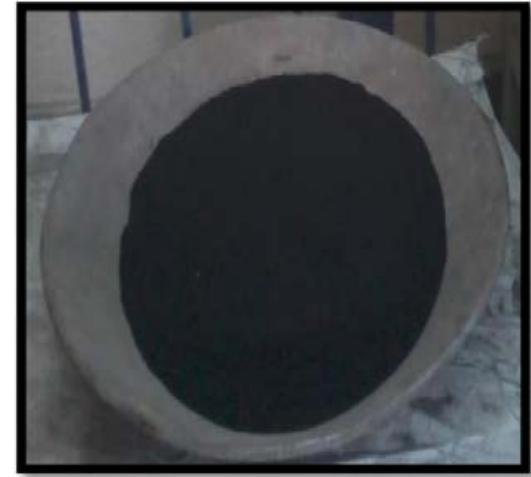

Figure 2. The image of waste foundry sand

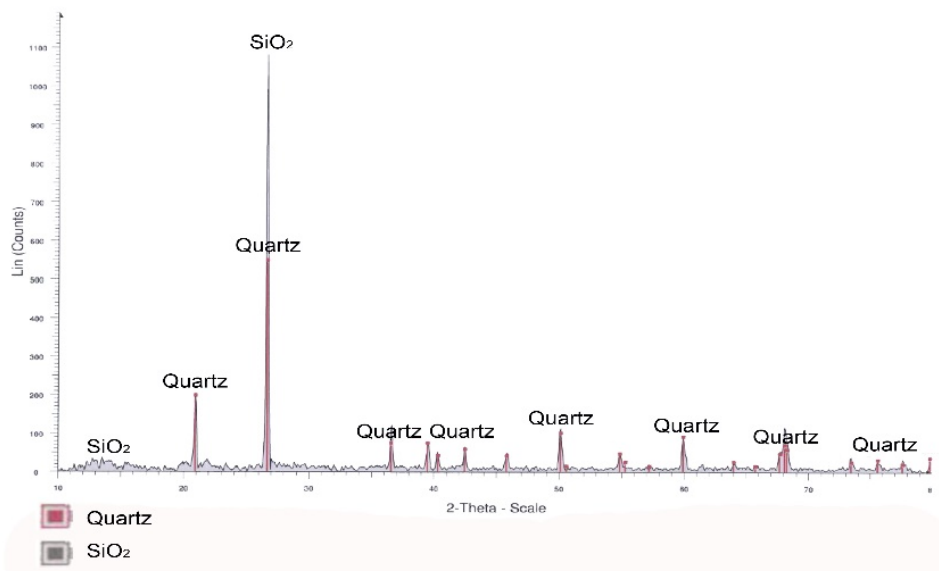

Figure 3. XRD analysis of waste foundry sand

\subsubsection{Aggregates}

Bank sand with various size of 0-4.75 mm was used. Unit weight of bank sand was equal to $2619 \mathrm{~kg} / \mathrm{m}^{3}$ and its water absorption ratio was equal to $3.6 \%$. Crushed gravel was used as coarse aggregate. Its unit weight was equal to $2700 \mathrm{~kg} / \mathrm{m}^{3}$ and its water absorption ratio was equal to $2.63 \%$. The maximum size of coarse aggregate was12.5mm. Physical properties of aggregates are shown in Table 2. 
Table 2. Physical properties of aggregates

\begin{tabular}{lccc}
\hline \multicolumn{1}{c}{ Property } & $\begin{array}{c}\text { Used-foundry sand } \\
\text { (UFS) }\end{array}$ & Regular sand (fine aggregate) & Coarse aggregate \\
\hline Specific gravity $\left(\mathrm{kg} / \mathrm{m}^{3}\right)$ & 2180 & 2619 & 2700 \\
SSD absorption (\%) & 0.42 & 3.6 & 2.63 \\
Fineness modulus & 1.9 & 2.55 & 5.96 \\
\hline
\end{tabular}

*SSD: Saturated Surface Dry

\subsubsection{Super plasticizer}

A polycarboxylic-based admixture acting as concrete super plasticizer has been used according to (ASTM C494 - Type G) to maintain the workability of concrete mixtures. It has a unit weight equal to $1.1 \mathrm{~kg} / \mathrm{litre}$ and its color is dark green.

\subsection{Mix proportions}

\subsubsection{Construction and maintenance of concrete samples}

Cubic mold $(15 \times 15 \times 15 \mathrm{~cm})$ was used to test the compressive strength and water absorption ratio. To conduct tensile strength and modulus of elasticity tests, cylindrical mold of $15 \times 30 \mathrm{~cm}$ dimensions was used. $7 \times 7 \times 28 \mathrm{~cm}$ prism mold was used to test the flexural strength. After preparing the concrete and casting it into the molds, samples are covered with the plastic sheets due to reduce the moisture loss and are cured at laboratory conditions at $23^{\circ} \mathrm{C}$ temperature for 24 hours. Then they were removed from mold after 24 hours and were kept in the water tank for 7 to 28 days as a curing process. Fig. 4 shows the samples made at present study.

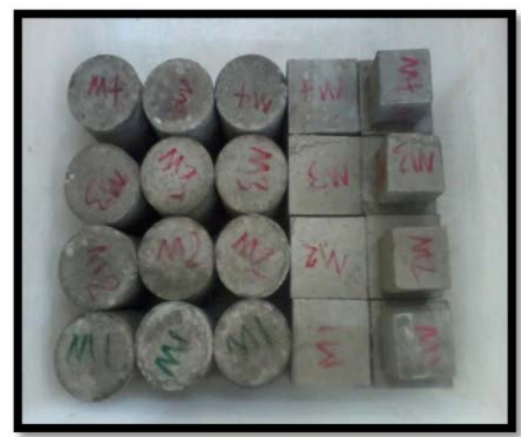

Figure 4. Cubic and cylindrical samples

\subsubsection{Mix designs specifications}

Three water-cement ratios $(0.4,0.45$ and 0.5$)$ have been used to make 24 mix designs. For the first 12 designs except control concrete, regular sand has been replaced with waste foundry sand with the percentages of 15,20 and 25. In the second 12 designs the first group were made but by replacing the consumed cement with $10 \%$ rice hull ash. The specifications of mix designs have been shown in Table 3.

\section{Experimental work}

\subsection{Compressive strength}

Compressive testing is determined in accordance with ASTM C39/C39M-17standard test method [16]. Compressive strength test results with loading speeds between 0.15 and $0.34 \mathrm{MPa} / \mathrm{s}$ and at the ages of 7 and 28 days have been shown in the Figs. 5, 6, 7 and 8. According to results, replacing regular sand with waste foundry sand causes a reduction in the compressive strength of concrete samples. This trend tends to increase by increasing replacement proportions (i.e., the more the replacement proportion, the less the compressive strength of the samples). In the water-cement ratio of $0.4,15 \%$ replacement regular sand with waste foundry sand caused a marginal reduction of $4.75 \%$. But 6.1 and $15.6 \%$ decline in compressive strength obtained for the sample containing 20 and 25\% waste foundry sand respectively compared to control sample at the age of 28 days. Compressive strength reductions in the samples with 0.45 water-cement ratio are equal to $6.1,11$, and $16.1 \%$ and for 0.5 water-cement ratio are equal to 13,14 and $15 \%$. So increasing water-cement ratio causes an increasing reduction in compressive strength of sample containing foundry sand. The existence of rice hull ash in designs comparing with the initial designs with water-cement ratio of 0.4 shows that there is $9.5 \%$ decrease in compressive strength at the age of 7 days; however, an increase equal to $2.5 \%$ occurs at the age of 28 days. In the water-cement 
ratio of 0.45 and 0.5 this increase in compressive strength is equal to $3.2 \%$ and $0.96 \%$ respectively. As obvious from the numbers, the highly effective use of rice hull ash is in designs with water-cement ratio of 0.45.

Table 3. Mix designs specifications

\begin{tabular}{ccccccccc}
\hline Mixture ID & w/c & $\begin{array}{c}\text { CEMENT } \\
\left(\mathrm{kg} / \mathrm{m}^{3}\right)\end{array}$ & $\begin{array}{c}\text { WATER } \\
\left(\mathrm{kg} / \mathrm{m}^{3}\right)\end{array}$ & $\begin{array}{c}\text { Rice husk ash } \\
\left(\mathrm{kg} / \mathrm{m}^{3}\right)\end{array}$ & $\begin{array}{c}\text { Coarse } \\
\text { aggregate }\end{array}$ & $\begin{array}{c}\text { Natural } \\
\text { sand }\end{array}$ & WFS & SP (cement \\
Wt\%)
\end{tabular}

* w/c: Water-Cement ratio; WFS: Waste Foundry Sand; SP: Super Plasticizer.

\subsection{Tensile strength}

Tensile strength test results at the ages of 7 and 28 days are shown in the Figs. 9, 10 and 11. Like compressive strength, replacing regular sand with foundry sand reduces tensile strength. For water-cement ratio of 0.4 , this reduction is 16,23 , and $26 \%$ in the replacement ratios of 15,20 , and $25 \%$ for age of 7 days and $11.1,25.9,27.7 \%$ for age of 28 days. By replacing $10 \%$ of the rice hull ash, the reduction would be 5, 23.9, and 25.6\% at the age of 28 days. This shows the beneficial effect of rice hull ash on tensile strength increase. On average, at the age of 28, tensile strength reductions for water-cement ratio of $0.4,0.45$ and 0.5 are equal to $21.6,30.5$ and $20.6 \%$ respectively. It can be seen that the most effective water-cement ratio for obtaining a better tensile strength when using foundry sand is 0.5 .

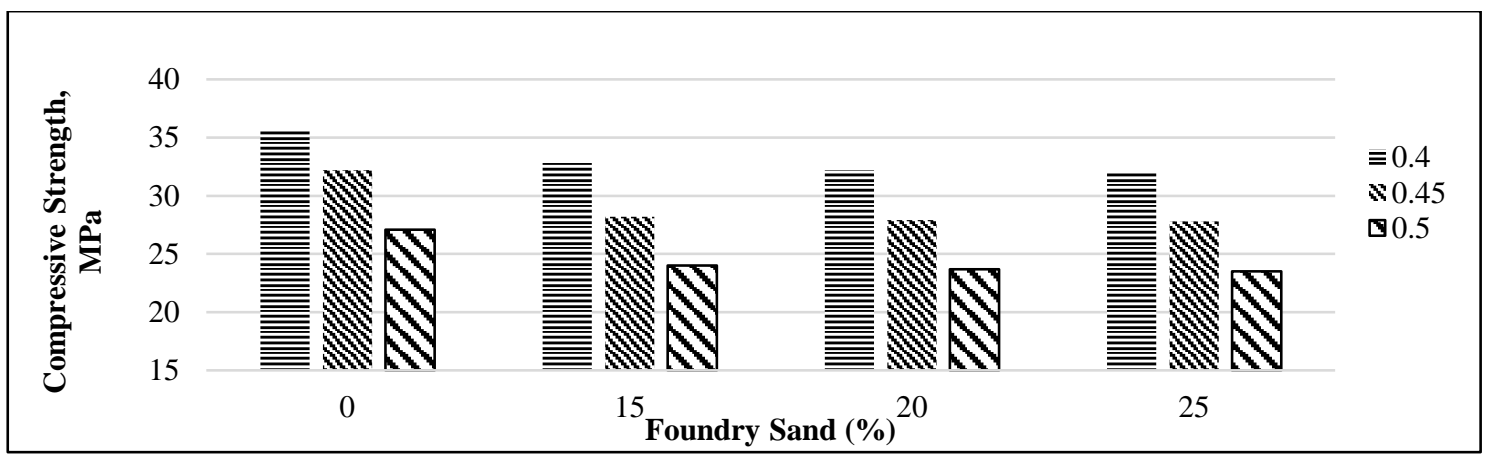

Figure 5. Compressive strength test results of mixes with waste foundry sand at the age of 7 days

\subsection{Flexural strength}

Flexural testing machine has been shown in Fig. 12. The results of flexural strength test are similar to that of compressive and tensile strength tests; that is, replacing the regular sand with foundry sand reduces the flexural 
strength comparing to the control concrete. According to Fig. 13, 14 and 15, flexural strength has been about 3.57.13MPa for the first 12 designs and about 3.62-7.28MPa for the second 12 designs containing rice hull ash. Prabhu et al. [11] have reported that the sand particles are the main reason for the strength reduction in the mixtures containing foundry sand. The smaller foundry sand grading comparing to the regular sand increases the water absorption of the particles in the sand surface and reduces the free water in concrete. The result of this phenomenon is reduction in fluidity and workability of concrete which makes the matrix structure of the concrete more porous and reduces the flexural strength.

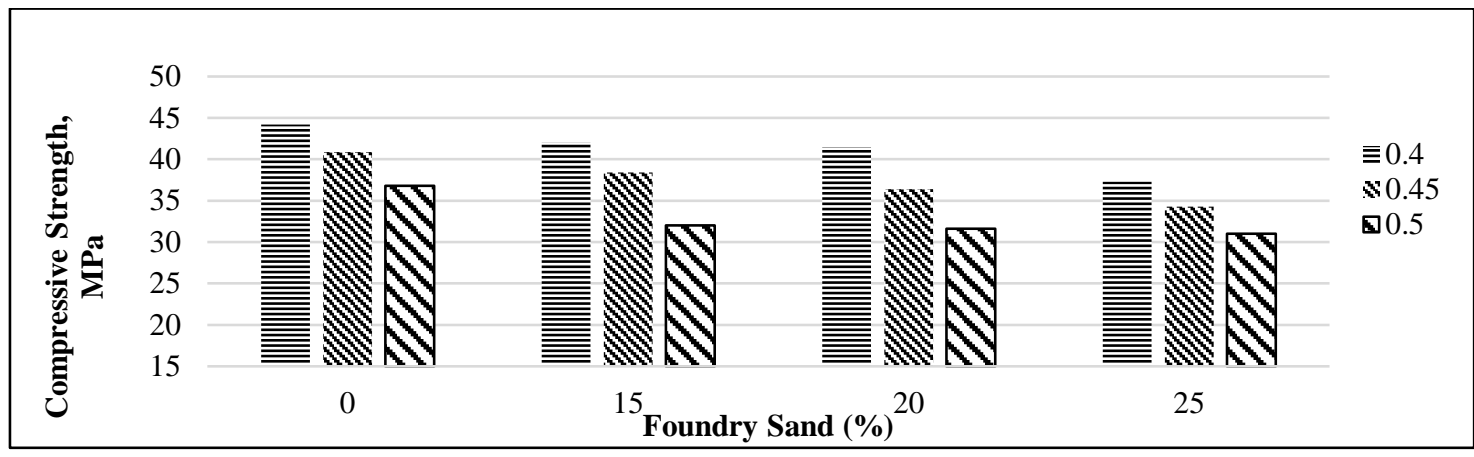

Figure 6. Compressive strength test results of mixes with waste foundry sand at the age of 28 days

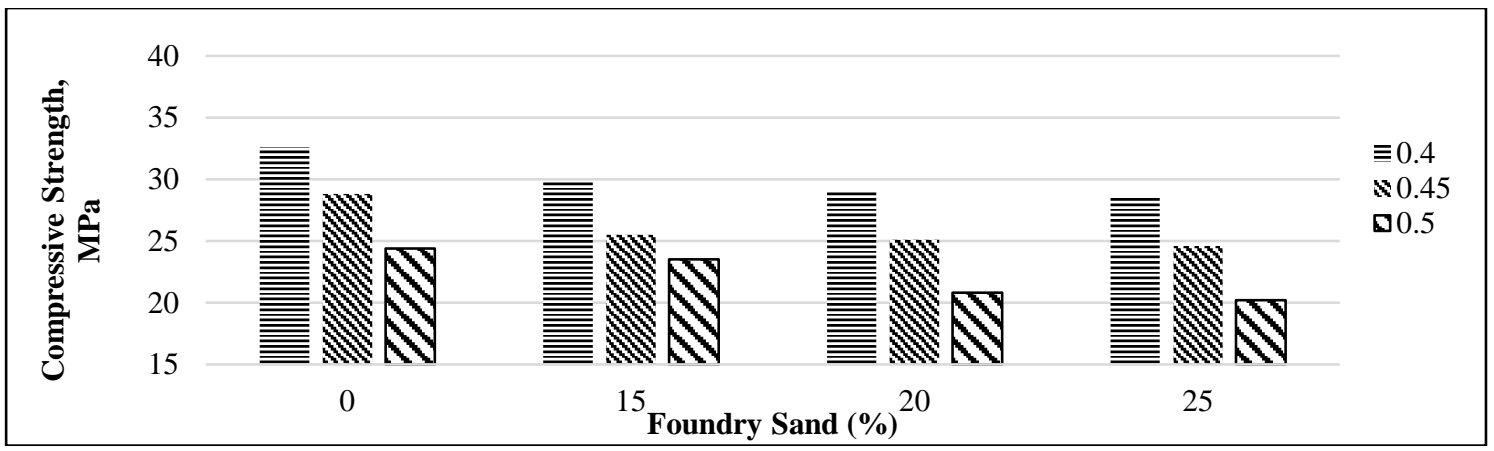

Figure 7. Compressive strength results in samples with both waste foundry sand and rice hull ash at the age of 7 days

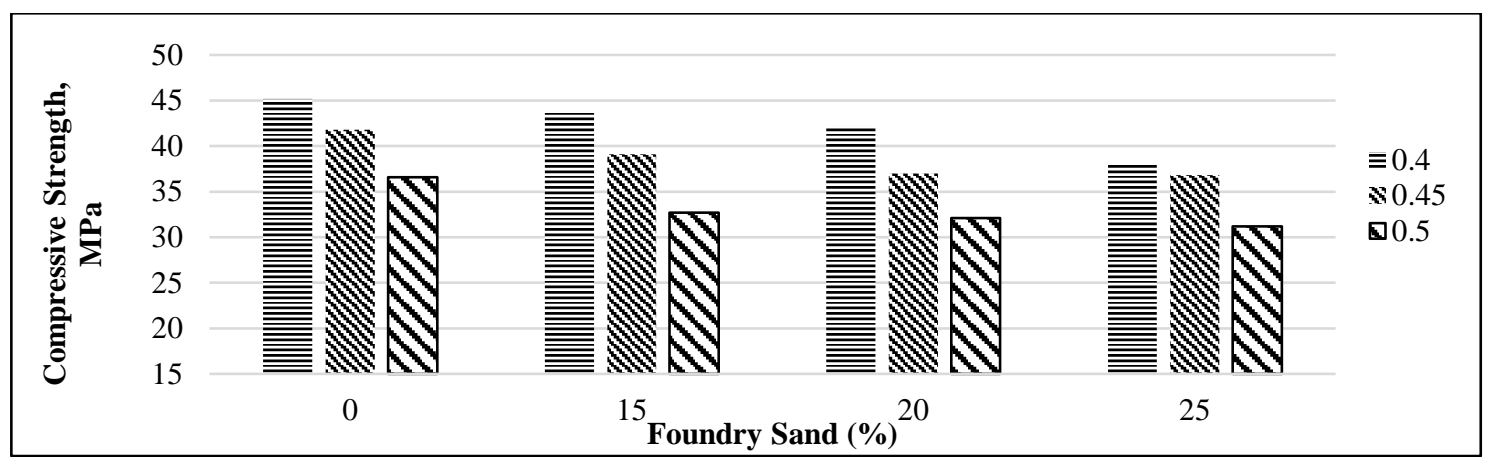

Figure 8. Compressive strength results in samples with both waste foundry sand and rice hull ash at the age of 28 days

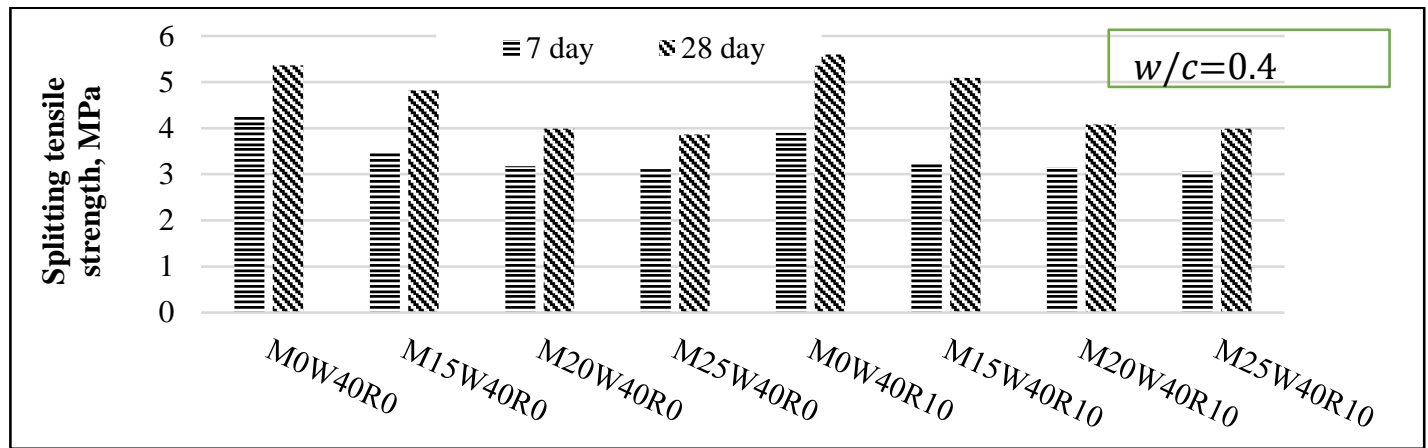

Figure 9. Tensile strength results in water-cement ratio of 0.40 


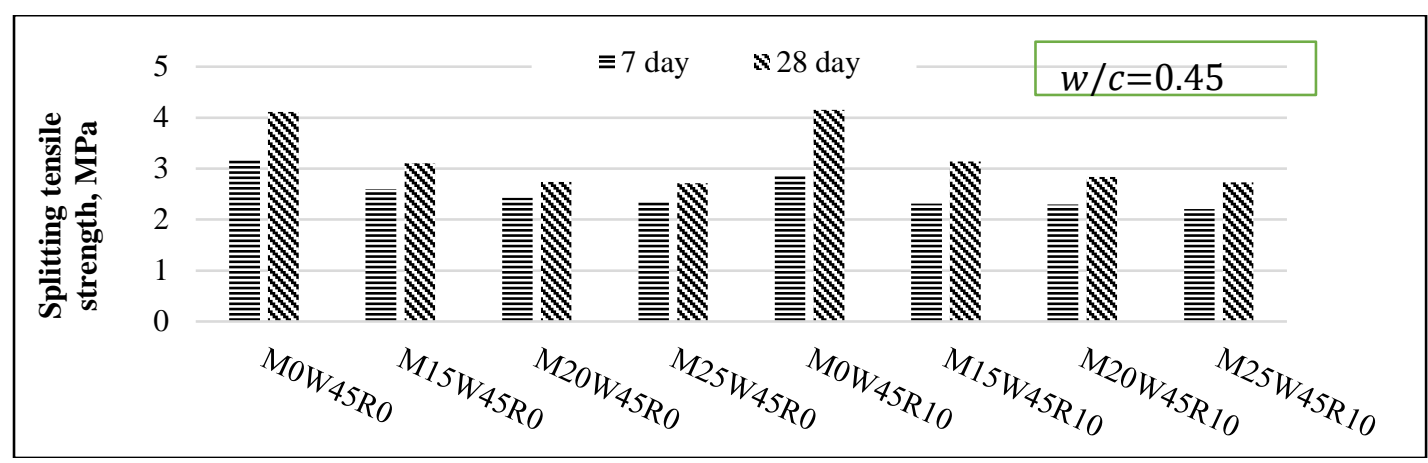

Figure 10. Tensile strength results in water-cement ratio of 0.45

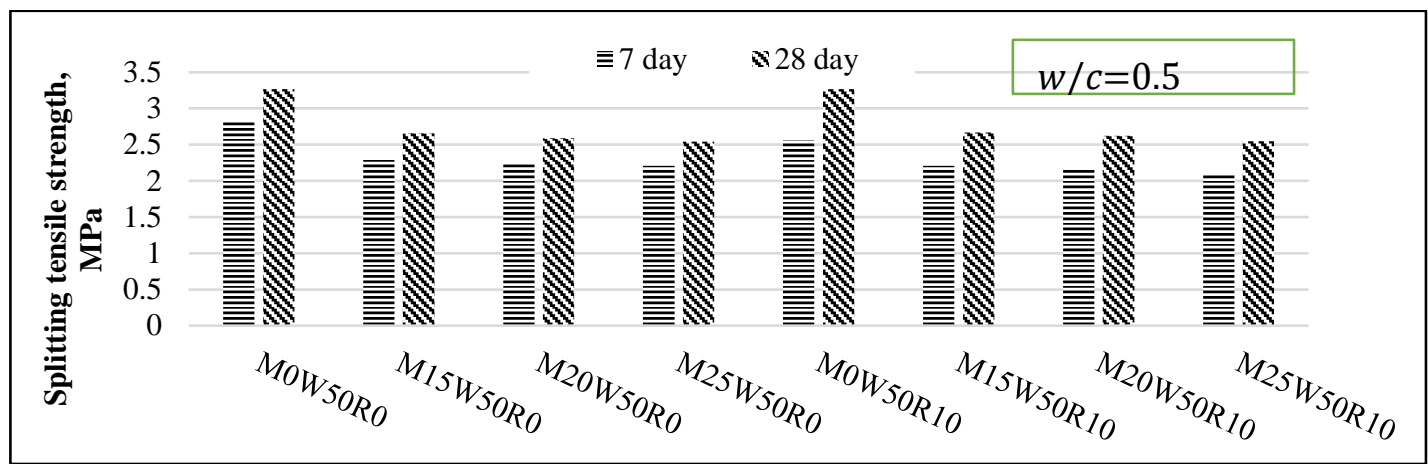

Figure 11. Tensile strength results in water-cement ratio of 0.5

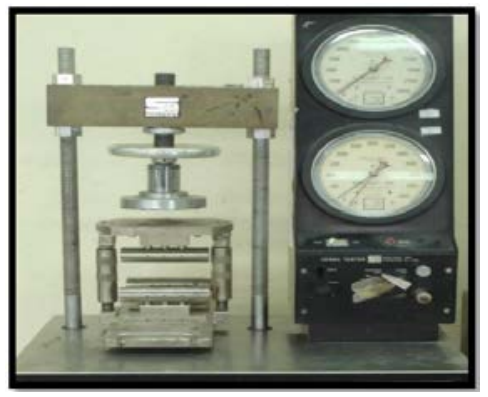

Figure 12. Flexural testing device

\subsection{Elasticity modulus}

The ASTMC496/C496M-14standard test method [17] is used to determine the modulus of elasticity. The results of elasticity modulus are shown in Figs. 16, 17 and 18. It could be seen that, by replacing the regular sand with the foundry sand in $15 \%$ design, the elasticity modulus is reduced by $13 \%$ for water-cement ratio of 0.4 . This reduction is equal to 14.2, and $14.5 \%$ for designs including 20 and 25\% replacement respectively. The average of elasticity modulus in designs containing foundry sand and designs containing both foundry sand plus rice hull ash in the water-cement ratio of 0.4 were 25.9GPa and 23.9GPa respectively. These are 21.5GPa and 19GPa respectively for the water-cement ratio of 0.45 and also $20.1 \mathrm{GPa}$ and $16.6 \mathrm{GPa}$ for water-cement ratio of 0.5 . These results show that adding pozzolana in all water-cement ratios will reduces elasticity modulus. This reduction rate increases by increasing the water-cement ratio. Basar et al. [6] reported that the reduction of elasticity modulus were 2.1, 6.9, 15.3 and $28.2 \%$ in the replacement percentages of 10, 20, 30 and 40\%. Unlike the results of compressive, tensile and flexural strength tests,the results of elasticity modulus test show that the rice hull ash has a negative impact on the elasticity modulus. In general, increasing water-cement ratio can have a negative impact and reduce the compressive, tensile and flexural strengths. Increase in water-cement ratio also reduces the elasticity modulus up to $20 \%$ in water-cement ratio of 0.4 comparing to water-cement ratio of 0.5 .

\subsection{Water absorption}

Comparing water absorption test results of designs in Fig. 19, 20 and 21 show that both replacements of regular sand with foundry sand and cement with rice hull ash increase the water absorption ratio of the samples. The highest water absorption ratios are equal to 2.7, 3.1 and 3.3\% respectively for three water-cement ratios of 0.4 , 0.45 and 0.5 and are associated with the design including $25 \%$ foundry sand as replacement of regular sand. 
Increase in water absorption is due to lower unit weight of foundry sand comparing to regular sand, therefore foundry sand fills the volume of concrete paste more than regular sand. In other word, by increasing the volume of aggregates in the mixture, the volume of transition area in the mixture and the effects of leakage formed around them will increase. According to BS 1881: Part 122 [18], the quality of concrete is divided into three categories; poor (>5\%), average (3-5\%) and good (0-3\%) for water-cement ratio. In this study, mix designs with water-cement ratio of 0.4 have water absorption between $1.2-2.7 \%$ for 28 days that they are classified as good. Water absorptions for mix designs with water-cement ratio of 0.45 and 0.5 are between $2.5-3.1 \%$ and $2.7-3.3 \%$ respectively where they are classified as average and good.

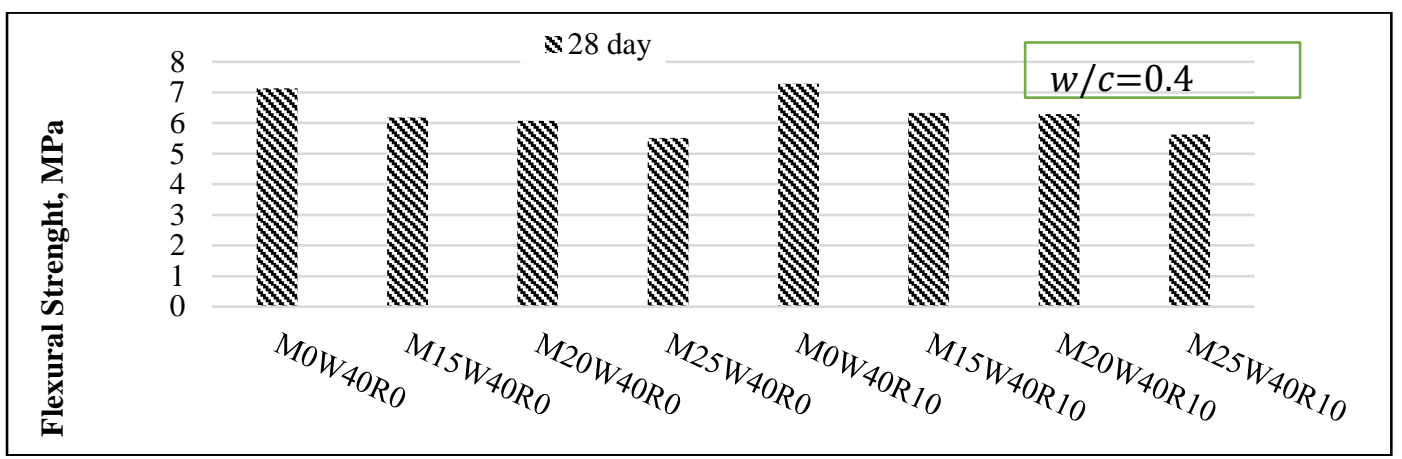

Figure 13. Flexural strength test results in the water-cement ratio of 0.4

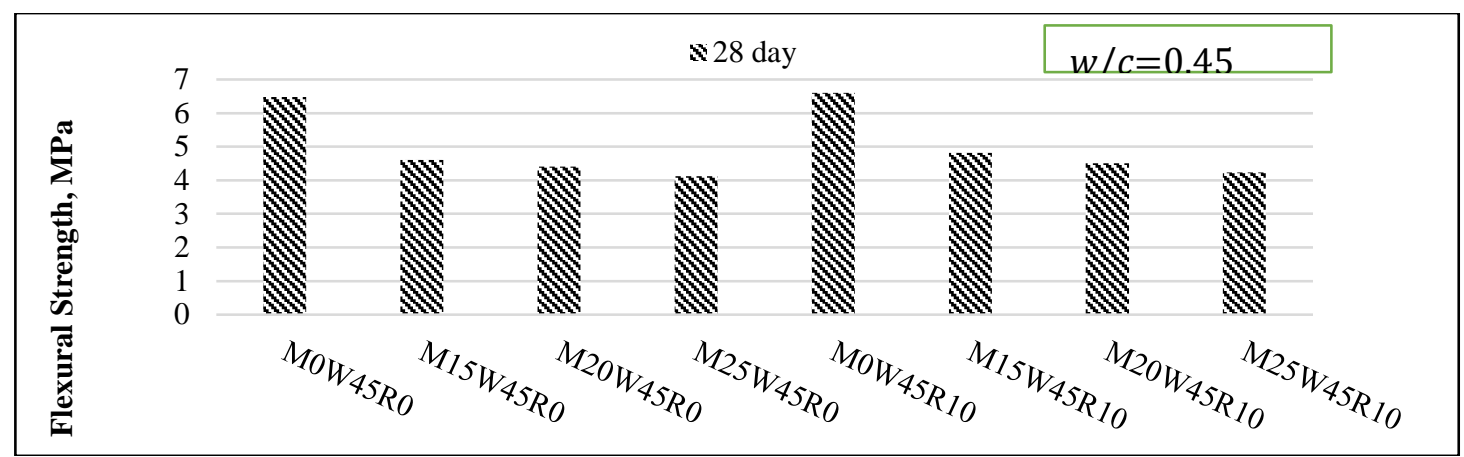

Figure 14. Flexural strength test results in the water-cement ratio of 0.45

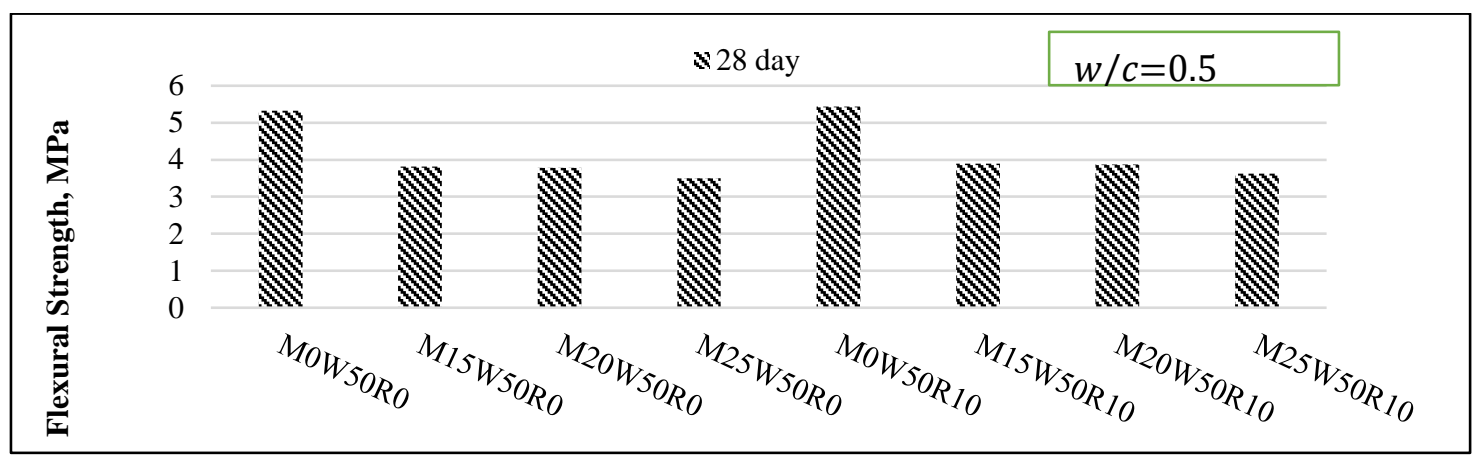

Figure 15. Flexural strength test results in the water-cement ratio of 0.5

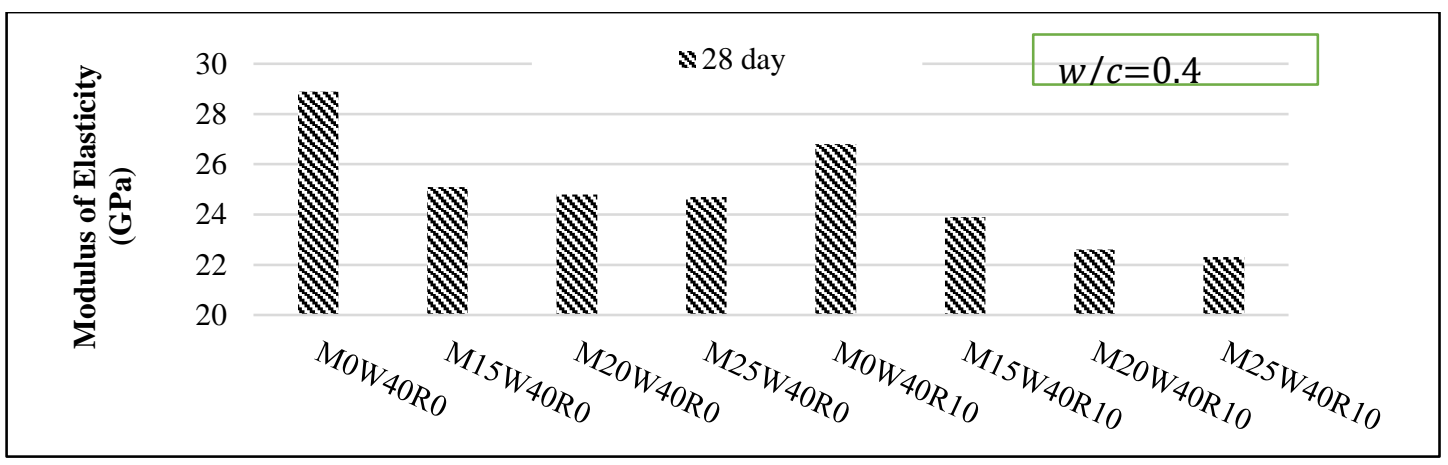

Figure 16. The results of elasticity modulus in the water-cement ratio of 0.4 


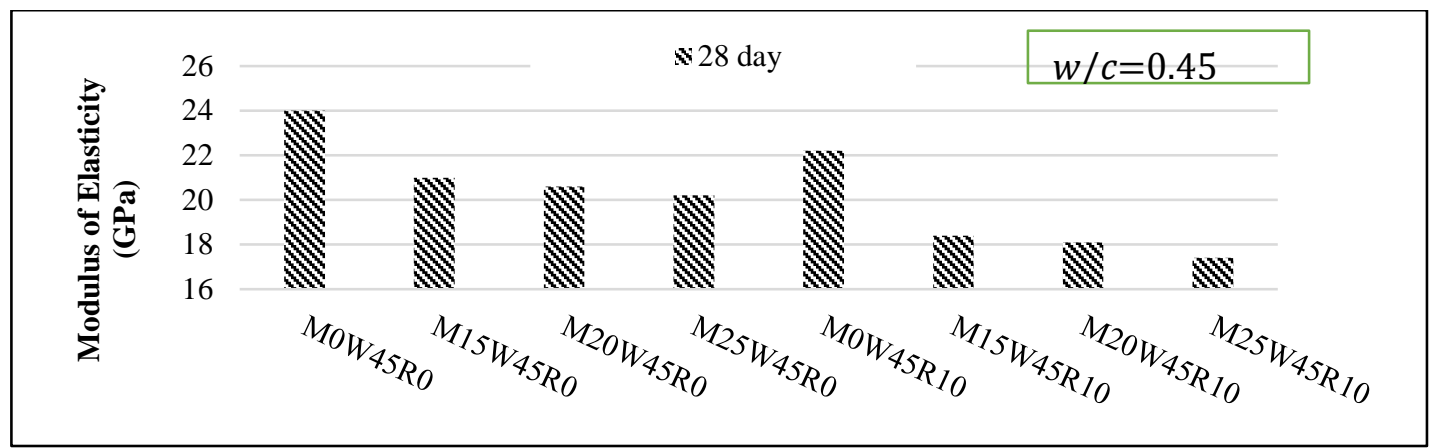

Figure 17. The results of elasticity modulus in the water-cement ratio of 0.45

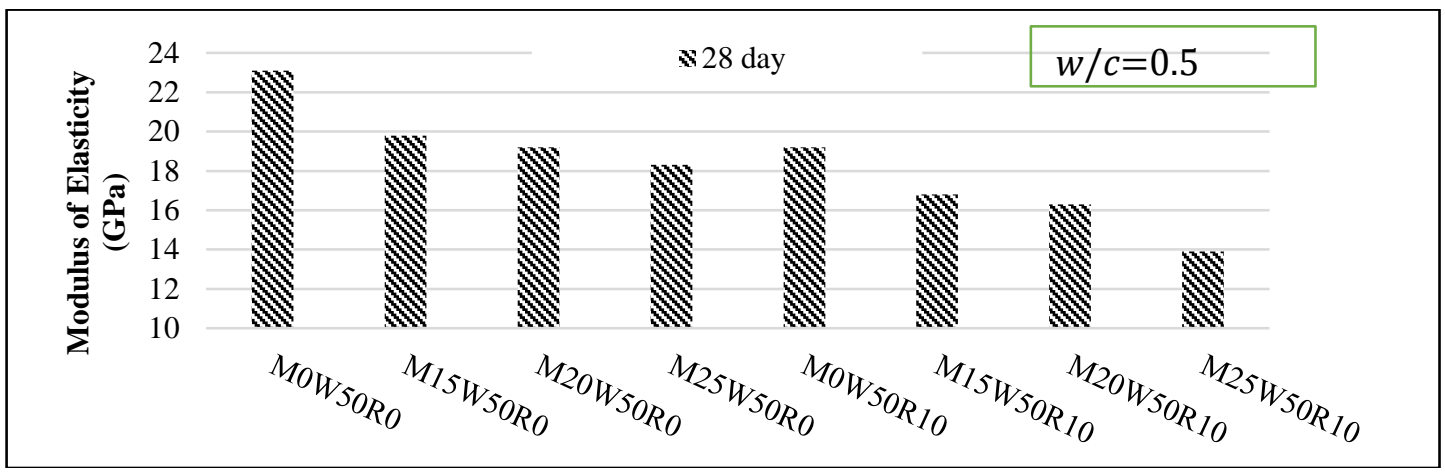

Figure 18. The results of elasticity modulus in the water-cement ratio of 0.5

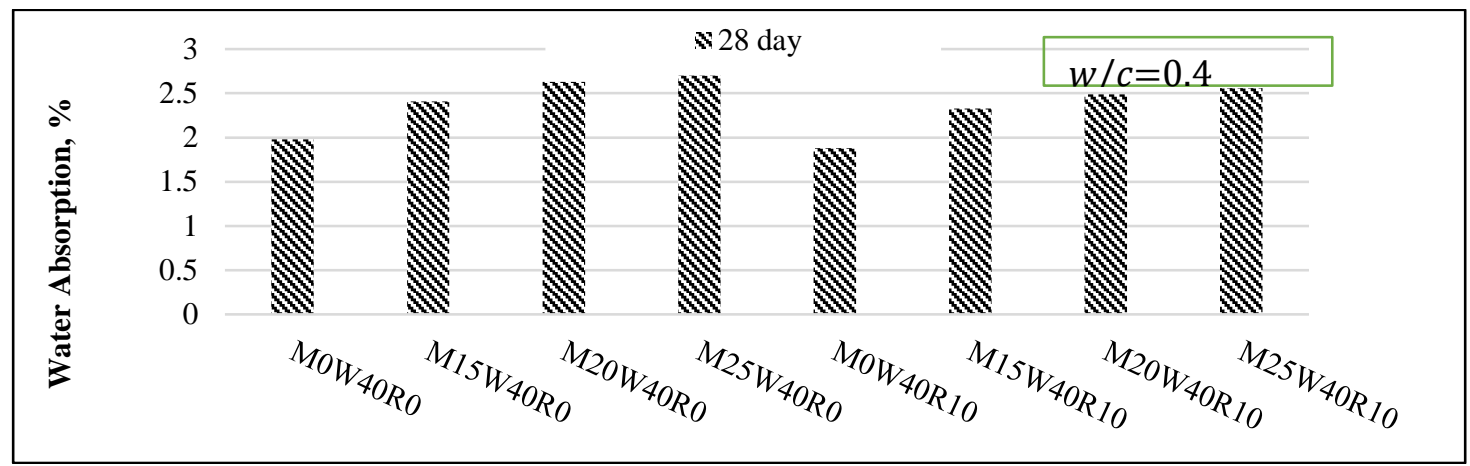

Figure 19. The results of water absorption in water-cement ratio of 0.4

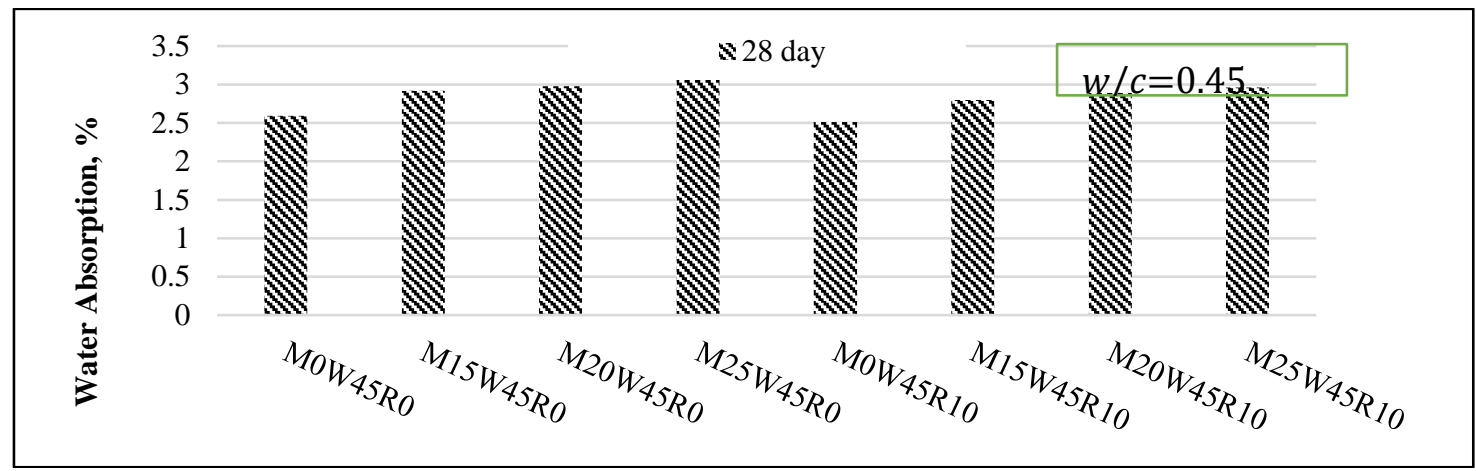

Figure 20. The results of water absorption in water-cement ratio of 0.45

\subsection{Scanning Electron Microscope (SEM) test results}

After beginning the hydration in cement, calcium, hydroxyl and aluminate ions which have obtained from dissolving the calcium sulfate and calcium aluminate in water are combined together and produce the calcium hydroxide and Ettringite. Since the main factor of the strength in the solid section of hydrated cement paste is Van der Waals forces, the adhesion between two surfaces of solid sections depends on these intermolecular forces. The degree of adhesion depends on the nature and the extent of these surfaces. Calcium hydroxide is a combination 
with a specific formula which is $\mathrm{Ca}(\mathrm{OH})_{2}$. This combination is usually formed from separated large crystals having hexagonal prismatic or plate forms. These crystals have large size and thus have a structure which is more porous than the crystals of the cement paste or mortar, hence cement paste weakens and reduces the strength of concrete. On the other hand after the compaction of fresh concrete, a thin layer of water is formed around coarse aggregates. This water causes the plate-form calcium hydroxide to be formed like crystals that are in a direction virtually perpendicular to the surface of the aggregate. This is the reason for the weakness of the area between the cement paste and aggregate (transition area).

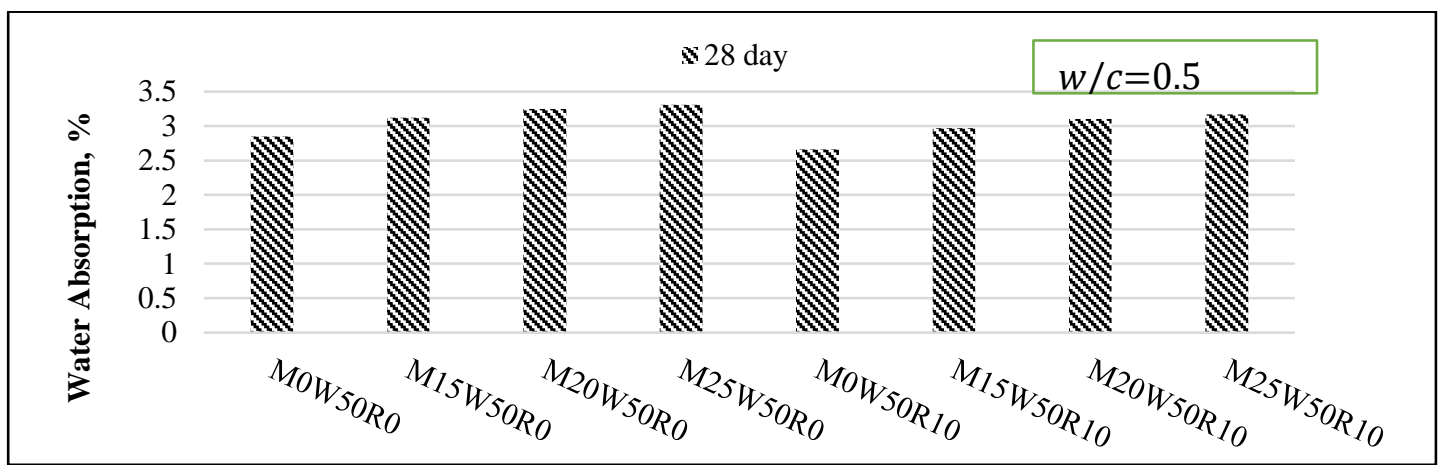

Figure 21. The results of water absorption in water-cement ratio of 0.5

Rice hull ash like other pozzolans reacts with the calcium hydroxide resulted from cement hydration and produces hydrated calcium silicate $\left(3 \mathrm{CaO} \cdot 2 \mathrm{SiO}_{2} \bullet 4 \mathrm{H}_{2} \mathrm{O}\right)$. C-S-H small crystals with hexagonal structure have a large lateral surface and thus considerable adhesion capabilities. Hydrated calcium silicate particles not only have a strong tendency to stick to each other but also adhere to the hydration products with smaller lateral surface that is calcium hydroxide, non-hydrated clinker particles and fine and coarse particles of the sand and gravel. This makes a reduction in the capillary pores in the concrete structure and increases the strength of pozzolanic samples. Fig. 22 shows mix design M25W40R0 containing 25\% foundry sand. Foundry sand contains 95\% silica sand with chemical formula $\mathrm{SiO}_{2}$. Point A in this figure is associated with the foundry sand in the concrete mixture. Fig. 23.A shows the Energy Dispersive X-Ray (EDX) analysis of this point which indicates the presence of silica and oxygen elements in foundry sand composition. This is a confirmation of existing silicon dioxide $\left(\mathrm{SiO}_{2}\right)$ elements. The cement in mix designs included 62.04\% lime combination $(\mathrm{CaO}), 21.3 \%$ Silica $\left(\mathrm{SiO}_{2}\right)$, 4.94\% Aluminum oxide $\left(\mathrm{Al}_{2} \mathrm{O}_{3}\right)$ and 3.08\% Magnesium oxide (MgO). Fig. 23.B is EDX analysis of the point $\mathrm{B}$ which is associated to the cement paste in concrete structure. EDX analysis shows the components of cement. Fig. 24 exhibits mix design M25W40R10 containing 25\% foundry sand and 10\% rice hull ash. Figs. 25.A and B are EDX analysis of two points of foundry sand in concrete mixture. The content of foundry sand is a combination of 95\% silica sand and alkaline elements such as $\mathrm{MgO}, \mathrm{Al}_{2} \mathrm{O}_{3}, \mathrm{~K}_{2} \mathrm{O}$ and $\mathrm{Na}_{2} \mathrm{O}$; however, the EDX analysis of the different parts of foundry sand indicates the elements $\mathrm{Si}, \mathrm{Al}, \mathrm{Mg}, \mathrm{O}$ and $\mathrm{K}$.

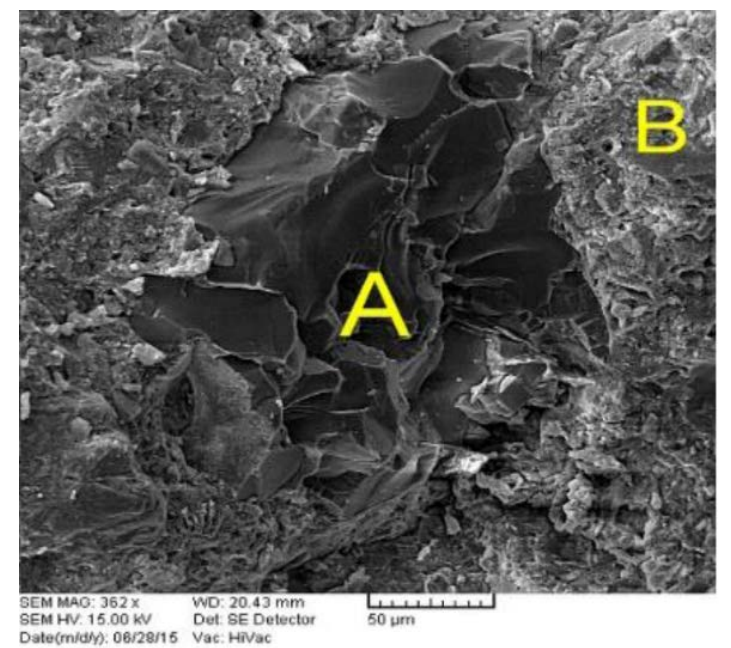

Figure 22. Electronic microscope image of mix design M25W40R0 

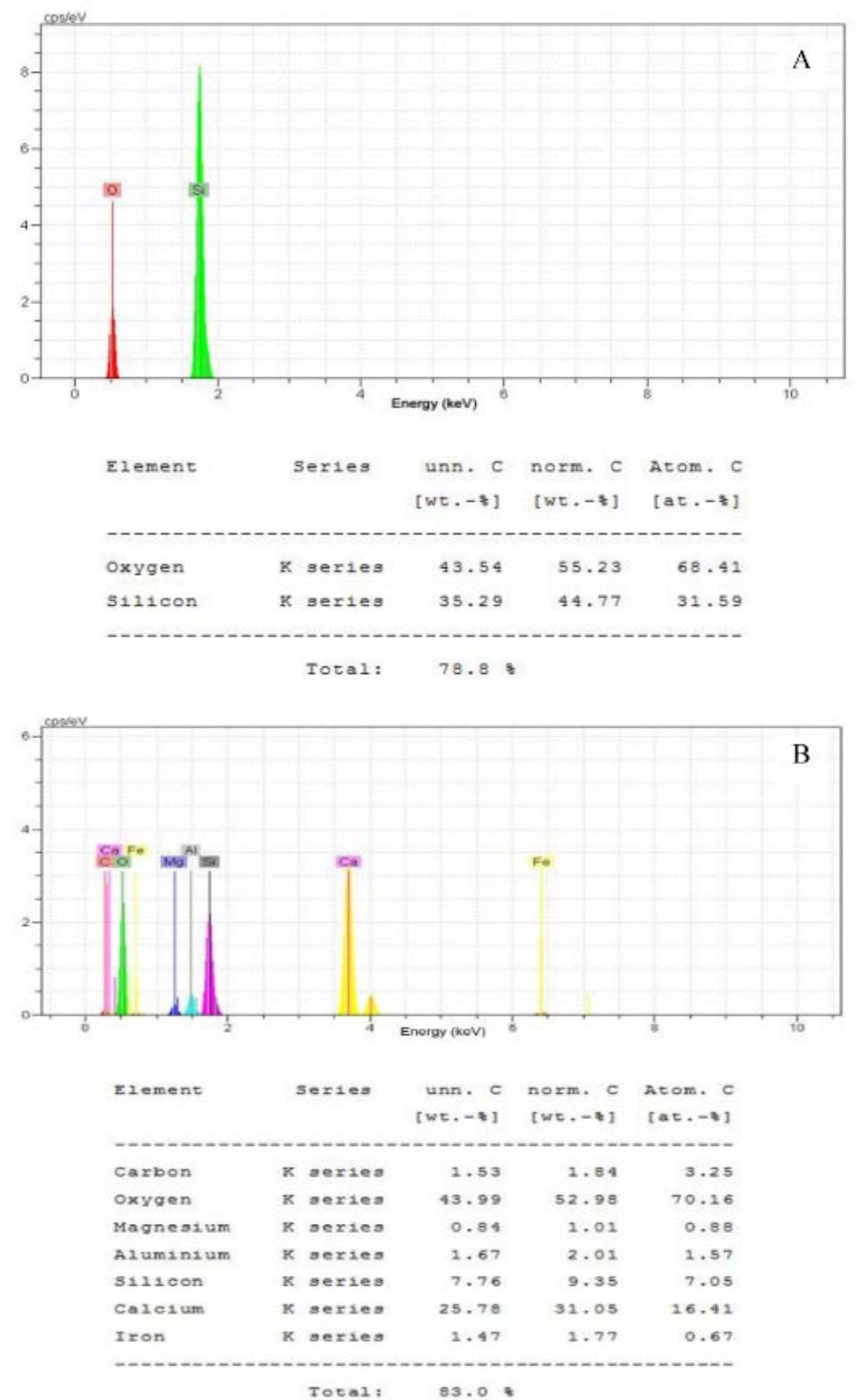

Figure 23. EDX analysis of mix design M25W40R0 for points A \& B

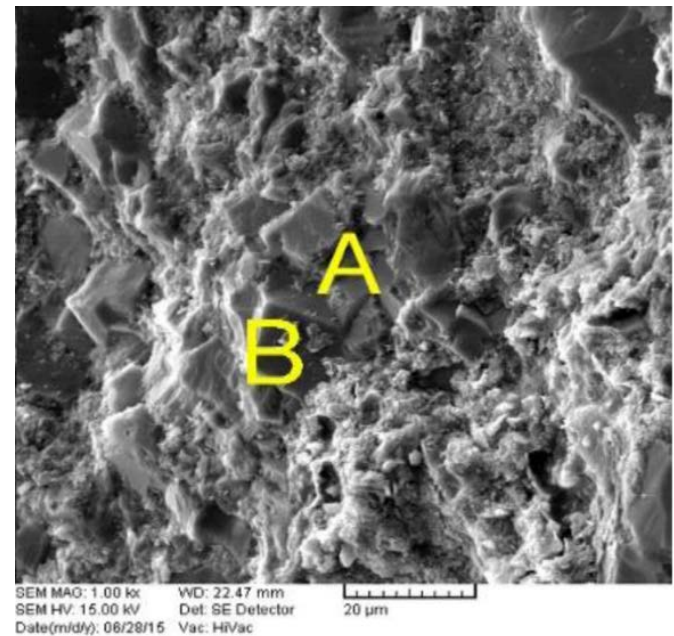

Figure 24. Electronic microscope image of mix design M25W40R10 

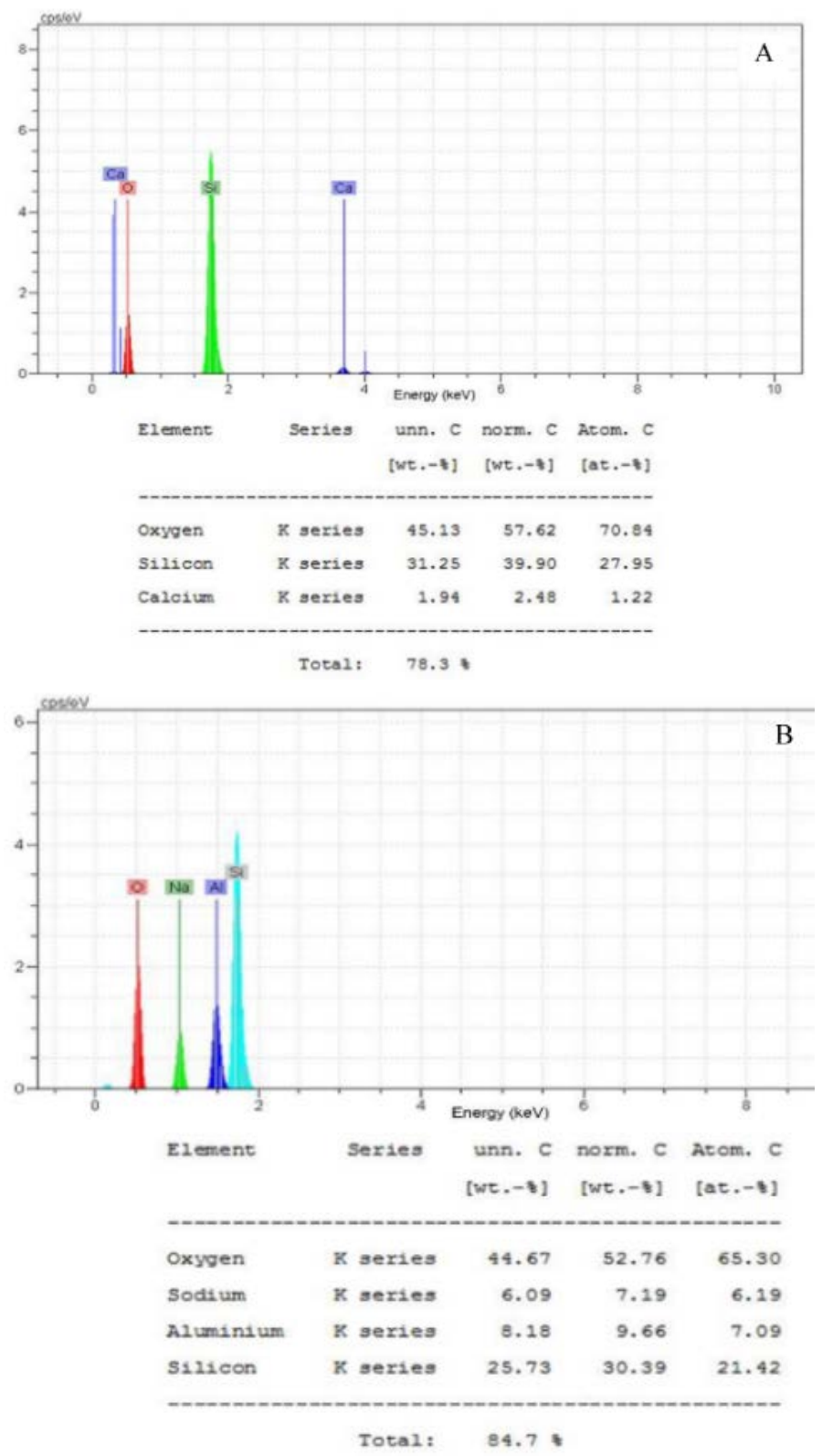

Figure 25. EDX analysis of mix design M25W40R10 for points A \& B

Fig. 26 shows the SEM image of mix design M0W40R10. Fig. 27 shows EDX analysis of point A in Fig. 26 that indicates there are the elements of silicon $(\mathrm{Si})$, oxygen $(\mathrm{O})$ and calcium $(\mathrm{Ca})$ in the aggregate compositions. These elements form the chemical structure of silicon dioxide $\left(\mathrm{SiO}_{2}\right)$ and calcium oxide $(\mathrm{CaO})$ in the aggregate composition. Fig. 28.A is electronic microscope image of control concrete mix design M0W40R0. Fig. 28.B is also associated to the M25W40R0 design that shows the microscopic structure of the design containing $25 \%$ foundry sand have capillary micro cracks and more pores comparing to the control design. These pores and cracks reduce the strength properties of M25W40R0 design concrete compared to the control design. Fig. 29.A is the electronic microscope image of control concrete mix design M0W40R0. In its structure, there are capillary micro cracks and calcium hydroxide particles with plate structure and perpendicular to the aggregates. According to the microscopic image of MOW40R10 design (Fig. 29.B), adding 10\% of the rice hull ash to the mix design caused calcium hydroxide from hydration process to turn into hydrated calcium silicate with crystal structure where it increases the concrete strength. The electronic microscopic image in Fig. 30.A is related to mix design M25W40R0 where it is easy to observe capillary cracks and pores in cement paste and also a rupture between cement paste and aggregate. But in the microscopic image in Fig. 30.B, adding the rice hull ash to M25W40R0 design forms hydrated calcium silicate. Using $10 \%$ of rice hull ash caused the concrete structure to be denser and also caused the cement paste to embrace the aggregate more cohesively. 


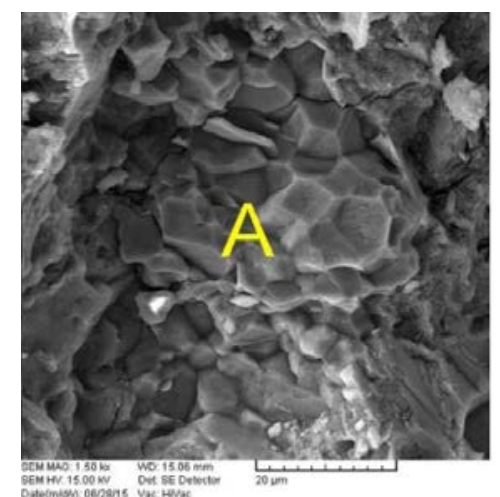

Figure 26. Electronic microscope image of mix design M0W40R10

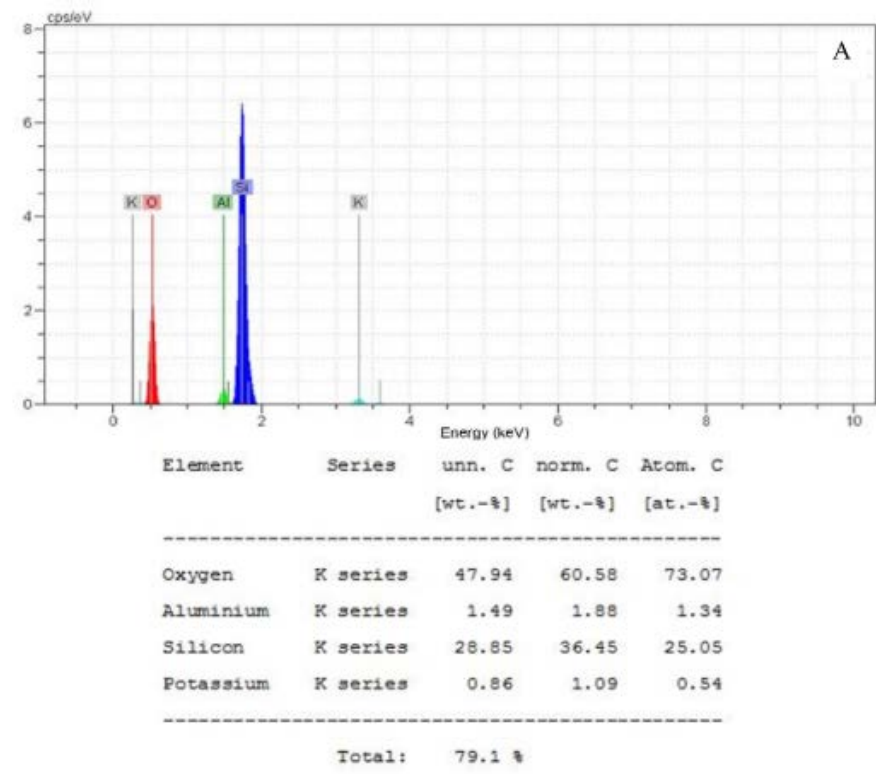

Figure 27. EDX analysis of mix design M0W40R10 for point A
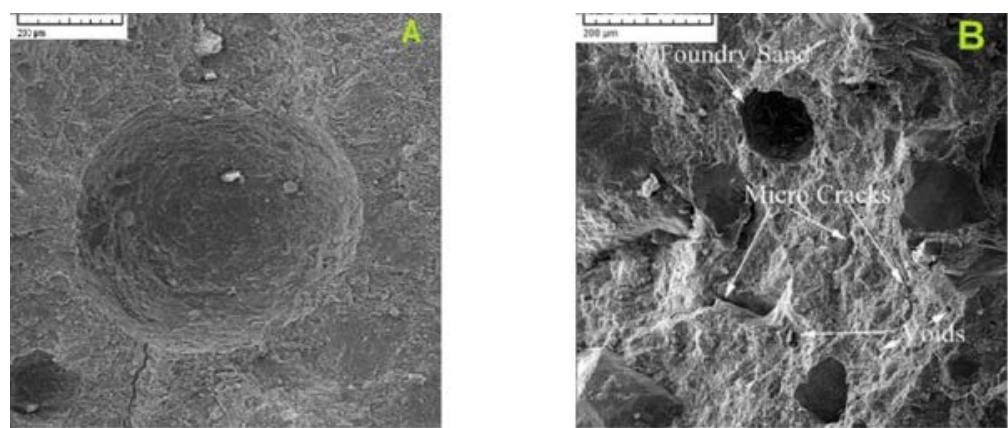

Figure 28. Electronic microscope image: (a) mix design M0W40R0, (b) mix design M25W40R0
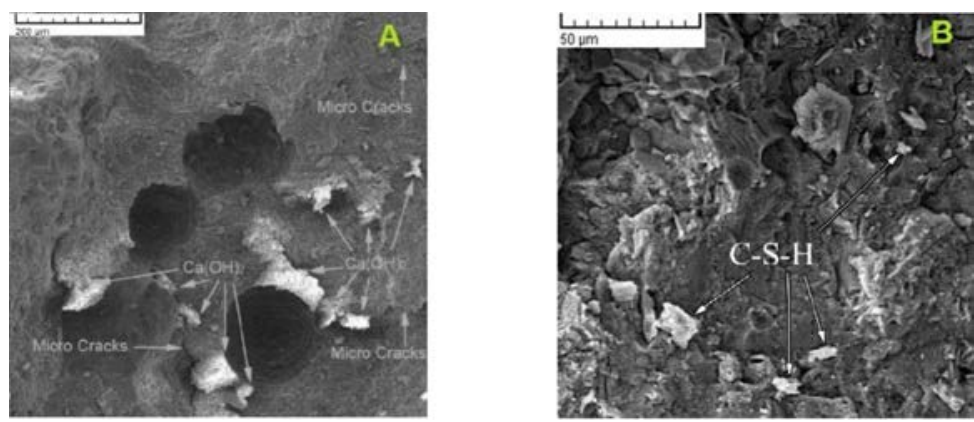

Figure 29. Electronic microscope image: (a) mix design M0W40R0, (b) mix design M0W40R10 

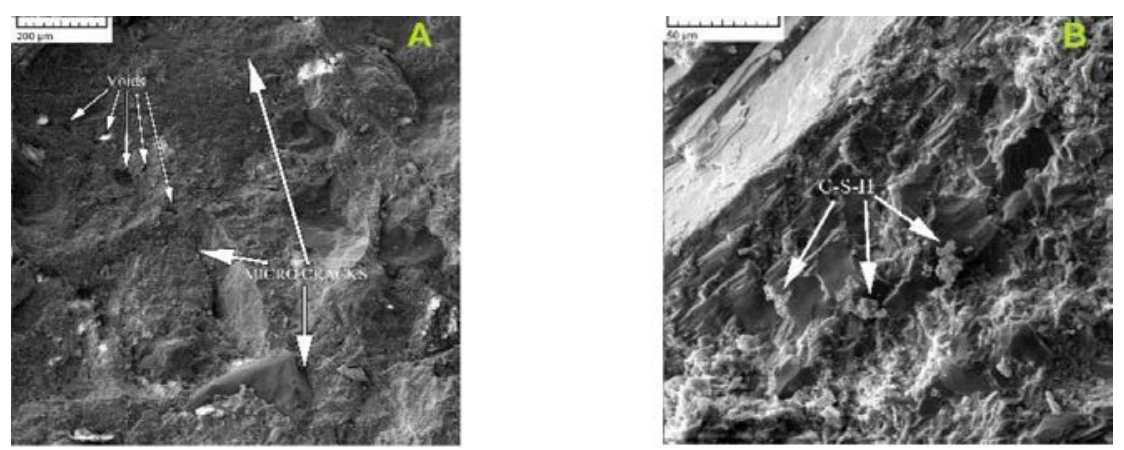

Figure 30. Electronic microscope image: (a) mix design M25W40R0, (b) mix design M25W40R10

\section{Conclusion}

The main objective of this study is to investigate the performance of the waste materials (foundry sand and rice hall ash) in concrete mixes. In addition to examining the mechanical properties of the produced concrete, its microstructure properties were also thoroughly investigated. The following conclusions are drawn from this study:

1) Compressive strength test results showed that in the water-cement ratio of 0.4 by replacing $15 \%, 20 \%$ and $25 \%$ of regular sand with foundry sand, the strength will be reduced by $4.75 \%, 6.1 \%$ and $11 \%$ respectively. However, all samples containing waste foundry sand satisfied the compressive strength requirements for structural concrete. Therefore, its use in concrete is both economically and environmentally suitable.

2) Using foundry sand in the designs reduces strength performances of the concrete such as tensile strength, flexural strength and elasticity modulus.

3) Using foundry sand in mix designs affects their physical performance where by increasing the replacement of regular sand with foundry sand, the water absorption of concrete samples increases.

4) Increasing the water-cement ratio in mix designs reduces the compressive strength, tensile strength, flexural strength and elasticity modulus. On the other hand, increasing the water-cement ratio increases the water absorption in the concrete samples in control design but increasing the replacement percentage of regular sand with foundry sand reduces its growth rate.

5) Using rice hull ash in mix designs increases the compressive, tensile and flexural strength. This shows that by using both $15 \%$ foundry sand, as a partial replacement of regular sand, and rice hull ash simultaneously, it is possible to make a concrete which its compressive strength is comparable with the concrete made of regular sand.

6) Unlike the results of compressive, tensile and flexural strengths, rice hull ash addition reduces the elasticity modulus and increases the water absorption in the concrete samples comparing to the samples without ash.

\section{References}

[1] Maier PL, Durham SA. Beneficial use of recycled materials in concrete mixtures. Construction and Building Materials. 2012;29:428-437.

[2] Cantero B, Bravo M, de Brito J, del Bosque IS, Medina C. Mechanical behaviour of structural concrete with ground recycled concrete cement and mixed recycled aggregate. Journal of Cleaner Production. 2020;275:122913.

[3] SHARMA RK, Gupta T, SHARMA S. Assessment of mechanical properties of concrete containing granite slurry waste. International Journal of Engineering. 2016;29(5):599-605.

[4] Bhardwaj B, Kumar P. Waste foundry sand in concrete: A review. Construction and Building Materials. 2017;156:661-674.

[5] Makul N. Combined use of untreated-waste rice husk ash and foundry sand waste in high-performance selfconsolidating concrete. Results in Materials. 2019;1:100014.

[6] Basar HM, Aksoy ND. The effect of waste foundry sand (WFS) as partial replacement of sand on the mechanical, leaching and micro-structural characteristics of ready-mixed concrete. Construction and Building Materials. 2012;35:508-515.

[7] Singh M, Siddique R. Properties of concrete containing high volumes of coal bottom ash as fine aggregate. Journal of Cleaner Production. 2015;91:269-278.

[8] Md S, Wahab A, Md AK. A study on the mechanical properties of concrete by replacing sand with waste foundry sand. International Journal of Emerging Technology and Advanced Engineering, 2013; 3(11): 83-88.

[9] Salokhe EP, Desai D. Application of foundry waste sand in manufacture of concrete. IOSRJMCE. 2014.

[10] Guney Y, Sari YD, Yalcin M, Tuncan A, Donmez S. Re-usage of waste foundry sand in high-strength concrete. Waste Management. 2010;30(8-9):1705-1713. 
[11] Prabhu GG, Hyun JH, Kim YY. Effects of foundry sand as a fine aggregate in concrete production. Construction and Building Materials. 2014;70:514-521.

[12] Pathariya Saraswati C, Rana Jaykrushna K, Shah Palas A, Mehta Jay G. Application of waste foundry sand for evolution of low-cost concrete. 2013.

[13] ASTM C150 / C150M-12. Standard specification for portland cement. West Conshohocken, PA. 2012.

[14] ASTM:E1621-13. Standard guide for elemental analysis by wavelength dispersive X-ray fluorescence spectrometry. 2010.

[15] BS EN 13925-1. Non-destructive testing-X-ray diffraction from polycrystalline and amorphous material-Part 1: General principles. 2008.

[16] ASTM C39/C39M-17. Standard test method for compressive strength of cylindrical concrete specimens. ASTM international: West Conshohocken, PA. 2017.

[17] ASTMC496/C496M-14. Standard test method for static modulus of elasticity and Poisson's ratio of concrete in compression. ASTM international: West Conshohocken, PA. 2014.

[18] BS 1881- part 12. Method for determination of water absorption. 2011.

(C) 2021 by the author(s). This work is licensed under a Creative Commons Attribution 4.0 International License (http://creativecommons.org/licenses/by/4.0/). Authors retain copyright of their work, with first publication rights granted to Tech Reviews Ltd. 